\title{
Uso de la fuerza letal. Muertos, heridos y detenidos en enfrentamientos de las fuerzas federales con presuntos miembros de la delincuencia organizada*
}

\author{
Carlos Silva Forné, Catalina Pérez Correa \\ y Rodrigo Gutiérrez Rivas
}

Debido al escaso conocimiento sobre los resultados del uso de la fuerza en enfrentamientos entre presuntos miembros de la delincuencia organizada y la Policía Federal, el Ejército y la Marina, el artículo presenta el saldo en materia de muertos, heridos y detenidos de 2008 a $201 \mathrm{I}$, a partir de dos fuentes: reportes de prensa y datos de la Secretaría de la Defensa Nacional. Se muestra que el índice de letalidad del Ejército se ha elevado sensiblemente desde 2008 hasta 201 I y que la relación de muertos sobre detenidos ha aumentado de 2009 a 201 I.También se expone que en comparación con la Policía Federal, el índice de letalidad es más alto para el Ejército y la Marina. El artículo advierte de los peligros implícitos de la participación del Ejército y la Marina en funciones de seguridad pública.

PALABRAS CLAVE: narcotráfico, fuerzas federales, uso de la fuerza letal, índice de letalidad, violaciones a los derechos humanos

Use of the Lethal Force. Dead, Wounded and Detainees during Armed Engagement of Federal Forces with Presumed Members of Organized Crime

Owing to the little information collected to measure the results of armed engagements between members of organized crime and the Federal Police, Army and Navy corps federal forces, this paper offers statistics concerning the results of such encounters occurred between 2008 and 20I I, collected from two sources: newspapers and data provided by the Mexican Ministry of Defense. Data analysis shows that Army and Marine lethality index is significantly higher than Police's. It also shows that the lethality index of the Army has increased considerably from 2008 to $20 \mathrm{II}$ and that the relation of deaths over detainees has also risen from 2009 to 20I I.The paper concludes cautioning about the implicit dangers when using the army and navy to achieve public security tasks.

KEYWORDS: drug trafficking, federal forces, use of lethal force, lethality index, human rights violations

CARLOS Silva Forné: Instituto de Investigaciones Jurídicas, Universidad Nacional Autónoma de México, Distrito Federal, México carlos_silvaforne@yahoo.com.mx
Catalina Pérez Correa: Departamento de Estudios Jurídicos, Centro de Investigación y Docencia Económicas, Distrito Federal, México catalina.perezcorrea@gmail.com

RoDrigo GutiéRREz Rivas: Instituto de Investigaciones Jurídicas,

Universidad Nacional Autónoma de México, Distrito Federal, México rod_gtz@hotmail.com

Desacatos, núm. 40, septiembre-diciembre 2012, pp. 47-64

Recepción: 14 de febrero de 2012 / Aceptación: 21 de marzo de 2012

\footnotetext{
* Agradecemos el apoyo de Karen Silva Mora y Benjamín Cervantes en la investigación de este trabajo.
} 


\section{INTRODUCCIÓN}

$\mathrm{E}$ l presente estudio surge con la intención de analizar a partir de información empírica la forma en que las fuerzas federales mexicanas - Policía Federal, Ejército y Marina- hacen uso de la fuerza - en particular de la fuerza letal - durante enfrentamientos. El estudio tiene su origen en un contexto en el que la participación de las fuerzas federales ha tenido un lugar central dentro de la estrategia del gobierno federal en el combate al narcotráfico. $\mathrm{Ha}$ habido un incremento notable en las quejas por presuntas violaciones a los derechos humanos presentadas ante la Comisión Nacional de Derechos Humanos (CNDH), así como de las tasas de homicidios dolosos y de delitos violentos en el país, especialmente para el caso de jóvenes. Partimos del supuesto de que si la información en torno al uso de la fuerza es insuficiente y ésta se ejerce con procedimientos de control inadecuados y determinación

eventual de responsabilidades aumenta la posibilidad de su abuso y, más preocupante, de abusos en el uso de la fuerza letal. Este resultado es aun más probable una vez que el gobierno federal ha tomado la decisión de recurrir al Ejército y a la Marina -instituciones cuyos integrantes están formados en el uso de la fuerza bajo contextos de guerra- para desempeñar tareas de seguridad pública. Dicho de otra forma, las características de la estrategia desarrollada por el gobierno federal incrementan la posibilidad de violaciones a los derechos humanos en el uso de la fuerza pública, en particular de la violación al derecho humano más importante: el derecho a la vida.

Este texto se divide en cinco partes. En la primera se describe el contexto en el que surge el estudio. Se destacan: a) el aumento en el número de operativos para el combate al narcotráfico realizados por la Secretaría de la Defensa Nacional (Sedena); b) el incremento en las quejas por presuntas violaciones a los derechos humanos presentadas ante la $\mathrm{CNDH}$ que señalan como responsable a la Sedena; c) el aumento de delitos violentos registrados en el país, en especial de homicidios. En la segunda parte se describe la metodología utilizada para medir el uso de la fuerza empleada por las fuerzas federales, para construir el índice de letalidad y encontrar las relaciones entre civiles muertos, civiles heridos y civiles detenidos en enfrentamientos contra las fuerzas federales. En la tercera parte se presentan los principales resultados obtenidos a partir de reportes de prensa y de información proporcionada por la Sedena por medio de solicitudes de información. En la cuarta parte se incluyen las definiciones y normas que se emiten sobre ejecuciones extrajudiciales desde el derecho internacional. Concluimos con una breve reflexión sobre las implicaciones que tienen los resultados de este estudio para la formulación de políticas en materia de seguridad pública, subrayando lo problemático que resulta el actual empleo del Ejército y la Marina para la realización de funciones en materia de seguridad pública.

\section{CONTEXTO}

Las tareas de seguridad pública - desde la prevención de delitos hasta la impartición de justicia, pasando por la investigación de delitos- son propias de las distintas instancias constitucionalmente creadas para esta función: policía, Ministerios Públicos y Poder Judicial. Las fuerzas armadas -Ejército, Armada y Fuerza Aérea- están diseñadas, en esencia, para cumplir funciones distintas a las de seguridad pública. Están entrenadas para combatir en contextos de guerra y realizar acciones de auxilio a la sociedad civil en ocasiones de emergencia, como lo establece la Ley Orgánica del Ejército y Fuerza Aérea Mexicanos en su artículo primero:

Art. 1. El Ejército y Fuerza Aérea Mexicanos, son instituciones armadas permanentes que tienen las misiones generales siguientes:

I. Defender la integridad, la independencia y la soberanía de la nación; 
Cuadro 1. Operaciones contra el narcotráfico realizadas por la Sedena

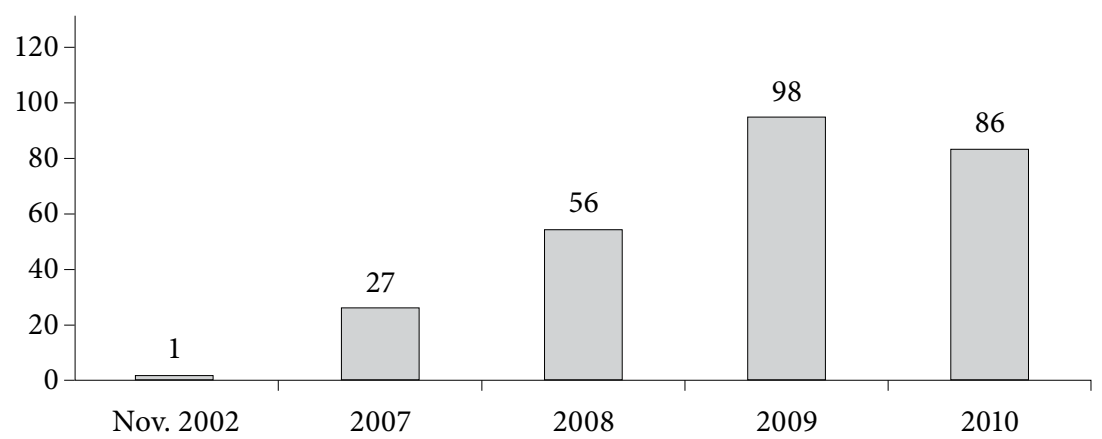

Fuente: Página electrónica: www.sedena.gob.mx.

II. Garantizar la seguridad interior;

III. Auxiliar a la población civil en casos de necesidades públicas;

IV. Realizar acciones cívicas y obras sociales que tiendan al progreso del país; $y$

V. En caso de desastre prestar ayuda para el mantenimiento del orden, auxilio de las personas y sus bienes y la reconstrucción de las zonas afectadas (Ley Orgánica del Ejército y Fuerza Aérea Mexicanos).

Las asignaturas de cada cuerpo de seguridad explican, al menos en parte, por qué ante situaciones parecidas miembros de las fuerzas de seguridad pública y de las fuerzas armadas responden de manera diferente. Cada una obedece al entrenamiento que ha recibido para cumplir con la función constitucionalmente asignada. No obstante, durante la administración de Felipe Calderón (2006-2012) se ha empleado a las fuerzas armadas en labores de seguridad pública, no sólo donde se acude al Ejército para realizar tareas de combate al narcotráfico, sino también en lugares donde las policías locales - consideradas deficientes o corruptas para garantizar la seguridad pública-han sido sustituidas con el Ejército o con las policías federales. En el caso del combate al narcotráfico, por ejemplo, de acuerdo con datos aportados por la Sedena a través del Instituto Federal de Acceso a la Información y Protección de
Datos Personales (IFAI, folio 0000700013611 ), ${ }^{1} \mathrm{a}$ partir de 2008 las operaciones en contra del narcotráfico llevadas a cabo por esa dependencia gubernamental aumentaron exponencialmente y se elevaron aun más durante 2009 y 2010 (véase cuadro 1).

Según los "Informes anuales" de la Sedena, no sólo los operativos, sino el número de elementos involucrados, aumentaron durante 2006 y 2009. De acuerdo con sus reportes anuales, de diciembre 2006 a septiembre 2007 el despliegue promedio anual de elementos militares para el combate al narcotráfico fue de 45723; entre septiembre de 2008 y septiembre de 2009, el promedio mensual fue de 48750, y para abril de 2011 este número fue de 49650 elementos (Sedena, 2006-2011).

\section{PARTICIPACIÓN DE LAS FUERZAS ARMADAS EN SEGURIDAD PÚBLICAY VIOLACIÓN A LOS DERECHOS HUMANOS}

En los últimos años, posiblemente como resultado de su mayor presencia en el territorio nacional, se han incrementado de manera notable las quejas

\footnotetext{
${ }^{1}$ Disponible en: <https://www.infomex.org.mx/gobiernofederal/ moduloPublico/rMedioElectP.action?idFolioSol=000070001361 1\&idTipoResp=6\#>.
} 
presentadas ante la CNDH por presuntas violaciones a los derechos humanos que señalan como responsable a la Sedena. En 2008, el número quejas en las que se atribuye a la dependencia presunta responsabilidad de violaciones a los derechos humanos se elevó más de 300\% (véase cuadro 2). De acuerdo con cifras de la $\mathrm{CNDH}$, el número de quejas contra la Sedena aumentó $677.4 \%$ de 2006 a 2010. Aunque el número de denuncias presentadas en la Comisión no es evidencia de que los miembros del Ejército estén cometiendo más violaciones a los derechos humanos, varios organismos de protección a los derechos humanos han documentado un número de abusos creciente por parte de los militares mexicanos, además de que han ligado la presencia en ascenso de cuerpos federales de seguridad con dichas violaciones (Meyer, Brewer y Cepeda, 2010; HRw, 2009 y 2012; AI, 2009).

Podría pensarse que el conocimiento que los ciudadanos han adquirido sobre sus derechos o acerca de la CNDH y su trabajo ha influido en el incremento de quejas. En ese caso veríamos un repunte en el total de número de quejas y no sólo en las presentadas contra una autoridad. Sin embargo, el número total de quejas registradas en la CNDH durante ese mismo periodo no tuvo una variación importante (véase cuadro 3), como sucedió con las quejas contra la Sedena, aunque sí se ve un ligero aumento desde 2007.

A partir de 2008, la Sedena se colocó como la autoridad más señalada como presunta responsable de violaciones a los derechos humanos, al adjudicársele ese año el mayor número de quejas entre las 493 autoridades involucradas en esas denuncias. La CNDH recibió un total de 6004 quejas por presuntas violaciones, de las que 1230 implican a la Sedena como presunta responsable, seguida por el Instituto Mexicano del Seguro Social (IMss) con 1007 quejas, la Procuraduría General de la República (PGR) con 769 quejas y la Policía Federal Preventiva (PFP) con 284 quejas. De nuevo en 2009 la Sedena ocupó el primer lugar entre 477 autoridades señaladas como presuntas responsables, con 1791 quejas en su contra, de un total de 6083 , y le siguieron el IMss con 701 quejas y la PGR con 680 quejas. En 2010, de 509 autoridades señaladas, la Sedena volvió a ocupar el primer lugar con 1415 quejas, de un total de 6916, y durante ese año el IMss tuvo 1083 quejas; la PFP, 595 y la PGR, 537.

Estos datos contrastan con los de 2007, cuando la Sedena ocupó el tercer lugar entre las 499 autoridades

Cuadro 2. Expedientes de queja en que se señala a la Sedena como presunta responsable de violación a los derechos humanos

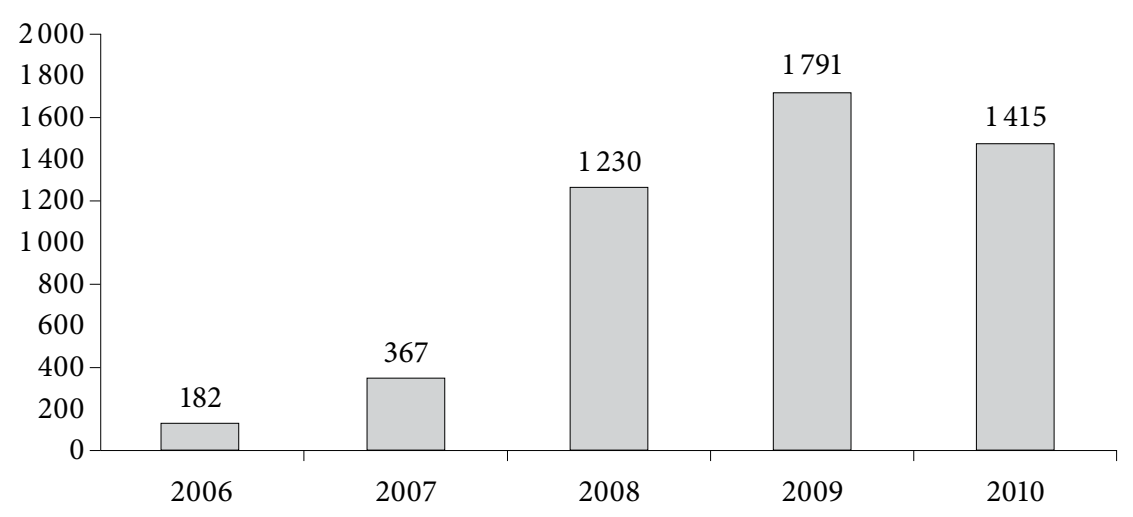


Tabla 1. Total de quejas registradas contra autoridades en la CNDH, 2006-2010

\begin{tabular}{lcccc}
\hline Año & $\begin{array}{c}\text { Expedientes de queja } \\
\text { registrados entre el } \\
\text { 1 de enero y el } 31 \\
\text { de diciembre }\end{array}$ & $\begin{array}{c}\text { Autoridades señaladas } \\
\text { como presuntas } \\
\text { responsables de violación } \\
\text { alos derechos humanos }\end{array}$ & $\begin{array}{c}\text { Expedientes de queja que } \\
\text { señalan como presunta } \\
\text { responsable a la Sedena }\end{array}$ & $\begin{array}{c}\text { Lugar que ocupa entre } \\
\text { las autoridades } \\
\text { señaladas como } \\
\text { responsables }\end{array}$ \\
\hline 2006 & 5475 & 487 & 182 & 9 \\
\hline 2007 & 5244 & 499 & 367 & 3 \\
\hline 2008 & 6004 & 493 & 1230 & 1 \\
\hline 2009 & 6083 & 477 & 1791 & 1 \\
\hline 2010 & 6916 & 509 & 1415 & 1 \\
\hline
\end{tabular}

Fuente: Informes de actividades, CNDH, 2006-2010, Comisión Nacional de Derechos Humanos, México, en línea: <http://www.cndh.org.mx>.

señaladas, con 367 quejas registradas, de un total de 5244, precedida por la PGR, con 671 quejas, y el IMss, con 1015. En 2006 la Sedena ocupó el noveno lugar de entre 487 autoridades señaladas como presuntas responsables, con un total de 182 quejas en su contra (véase tabla 1). En relación con las recomendaciones emitidas por la CNDH dirigidas a la Sedena, también se aprecia un aumento en los últimos años. De no emitirse ninguna recomendación en 2006, en 2007 se emitieron seis, 14 en 2008, 30 en 2009 y 22 durante 2010.

\section{Delitos violentos y homicidios}

En los últimos años, el número de delitos violentos cometidos, sobre todo el homicidio doloso, se han incrementado. En tal sentido, cifras y análisis recientes han advertido que:

El número de delitos violentos ha crecido significativamente en los últimos años. Entre 2007 y 2010, los asaltos a bancos aumentaron 90\%. En el mismo periodo los delitos de extorsión se elevaron $100 \%$, los robos de auto con violencia $108 \%$ y los secuestros 188\% (Guerrero, 2011).

La tasa de homicidios dolosos a nivel nacional ha crecido de manera acelerada de 2008 al 2010, revirtiendo el descenso de las últimas dos décadas: de 9.7 homicidios dolosos por cada 100000 habitantes en 2007 a 17.9 en 2010 (Secretariado Ejecutivo, 2010).
Si bien el incremento ha sido en casi todos los estados del país, los más importantes, dramáticos en algunos casos, se han concentrado en una decena de estados: Chihuahua, Baja California, Durango, Sinaloa, Nuevo León, Tamaulipas, Guerrero, Michoacán, Nayarit, Morelos (Secretariado Ejecutivo, 2010).

Los jóvenes son el grupo más afectado por los homicidios. En 2009 la principal causa de muerte violenta en personas entre 15 y 44 años fue el homicidio, principalmente por arma de fuego (Cervantes, 2011).

Existe una correlación estadística y un posible impacto causal entre la presencia del Ejército y de la Policía Federal en operativos conjuntos y el aumento de las tasas de homicidios dolosos, que se verifica para todas las bases de datos disponibles sobre el tema y que se observa tanto a nivel estatal como municipal (Escalante, 2011; Merino, 2011).

Sobre el establecimiento de los mecanismos causales específicos que expliquen con precisión por qué han aumentado la violencia y los homicidios en el país, se han llevado a cabo análisis empíricos para estudiar la vinculación de la detención de capos con la fragmentación de los grupos delictivos y la intensificación de la violencia (Guerrero, 2011). Se han señalado otras hipótesis que demandan la realización de investigaciones de mayor profundidad acerca de la alteración de los órdenes y arreglos locales que puede haber significado la presencia de fuerzas federales. Siguiendo esta idea, el crecimiento de la violencia reflejada en la tasa de homicidios dolosos involucraría también a actores ajenos a la ecuación 
Cuadro 3. Número de quejas por presuntas violaciones a los derechos humanos presentadas ante la CNDH

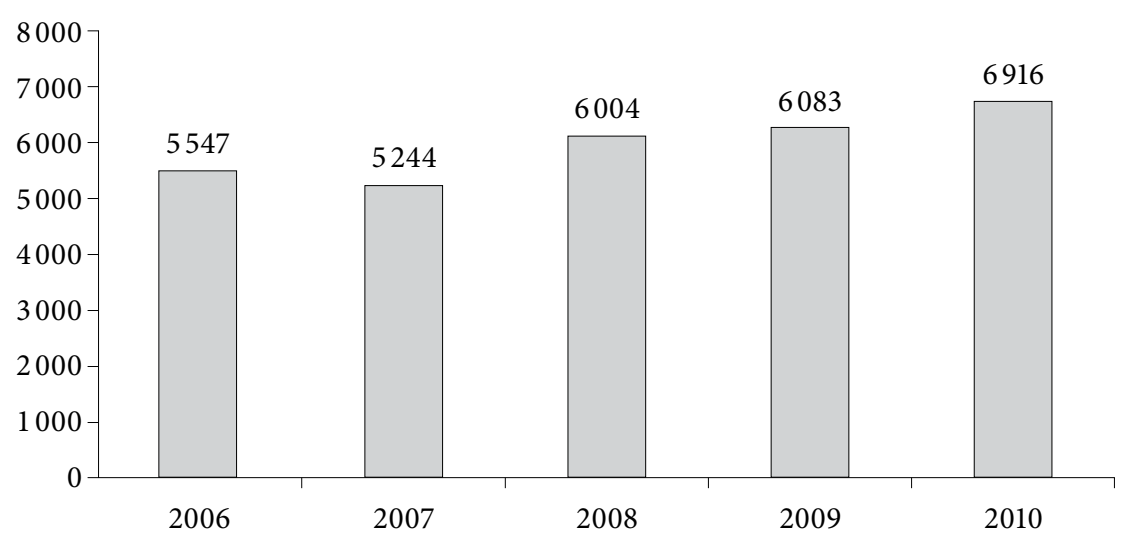

Fuente: Informes de actividades, CNDH, 2006-2010, Comisión Nacional de Derechos Humanos, México, en línea: <http://www.cndh.org.mx>.

siempre recurrida de las disputas y enfrentamientos entre los grupos de delincuencia organizada y la

\section{METODOLOGÍA}

En esta sección describimos las principales características metodológicas de este estudio y algunas limitaciones que deben tomarse en cuenta. La evaluación sobre la razonabilidad en el uso de la fuerza por parte del Ejército, la Marina y la Policía Federal es un fenómeno de aprehensión difícil, pero que es posible conocer a partir de algunos indicadores. Estudiamos el fenómeno a partir de dos fuentes: 1) recopilando información de prensa entre enero de 2008 y mayo de 2011 sobre enfrentamientos entre fuerzas federales y presuntos miembros de la delincuencia organizada para construir una base de datos anotando el número de muertes y heridos de ambos bandos, y 2) comparamos esta información con los datos proporcionados por la Sedena sobre heridos, muertos y detenidos.

\section{Base de datos de enfrentamientos de enero de 2008 a mayo de 20 I I}

La unidad de análisis de la base de datos es un enfrentamiento entre integrantes de fuerzas de seguridad federales - Policía Federal, Ejército y Marina- y presuntos miembros de organizaciones criminales. Se consideró como enfrentamiento aquel evento en el cual presuntos miembros de organizaciones criminales sostuvieron un intercambio de fuego con integrantes de las mencionadas fuerzas de seguridad. No se incluyeron agresiones o ataques por parte de presuntos miembros de grupos de delincuencia organizada a instalaciones y/o elementos de fuerzas federales durante los que no se registró dicho intercambio en el uso de las armas de fuego. La consideración de los civiles que participan en el enfrentamiento como parte de "grupos de delincuencia organizada" y no como delincuentes "comunes" u "ocasionales" se estableció a partir de lo que consignaba y clasificaba la propia nota de prensa. El nivel de detalle de la información no permitía la introducción de criterios más exigentes, 
como el número de participantes en el enfrentamiento o el tipo de armamento que portaban. En los enfrentamientos pudieron haber participado fuerzas de seguridad locales, lo cual quedó anotado en cada evento, pero sólo se registraron enfrentamientos en los que participó al menos una de las fuerzas federales mencionadas.

Las fuentes de información para la base de datos fueron los archivos digitales de dos periódicos de distribución nacional: El Universal y La Jornada. ${ }^{2}$ Las principales variables a recopilar para cada enfrentamiento fueron: fecha, entidad federativa de ocurrencia, tipo de fuerza federal presente, número de fallecidos de cada fuerza federal presente, número de fallecidos civiles presuntamente miembros de grupos criminales, número de fallecidos civiles accidentales, número de heridos de cada fuerza federal presente, número de heridos civiles presuntamente miembros de grupos criminales y número de heridos civiles accidentales. Además, se solicitó información sobre enfrentamientos, fallecidos, heridos y detenidos a la Sedena y se recabaron datos al respecto en su Portal de Transparencia.

\section{Indicadores del abuso de la fuerza en enfrentamientos}

La preocupación por el uso de la fuerza en enfrentamientos entre autoridades y presuntos delincuentes tiene antecedentes para el caso de las policías, y ha sido objeto de reflexión en varios países de América Latina donde el uso excesivo de la fuerza ha sido registrado y estudiado, por ejemplo en Brasil, Argentina

\footnotetext{
${ }^{2}$ Para que el enfrentamiento fuera incluido en la base de datos debía ser reportado en los dos diarios. Si las cifras de muertos o heridos no coincidían en los dos periódicos, se consultaba un tercero de distribución nacional - Reforma-, o un cuarto - La Crónica de Hoy - si el tercero no registraba el evento. Si las cifras de la tercera fuente coincidían con las de uno de los dos primeros diarios, se registraban esas cifras. Si continuaban sin coincidir se recurría a una regla de registro por la que debíamos considerar el
}

o Venezuela (Cano, 2003, 2010; CELs, 2002; Birkbeck y Gabaldón, 2002). El uso de la fuerza en enfrentamientos puede resultar problemático porque, en su contexto, puede ser legítimo y legal quitarle la vida a otra persona. Sin embargo, la experiencia ha mostrado que en algunos casos la autoridad involucrada puede sostener que hubo un enfrentamiento para justificar el uso de la fuerza letal aunque no haya habido tal. O que existiendo el intercambio de fuego se usara la fuerza letal de forma excesiva. En estos casos, si no contamos con descripciones adecuadas de los eventos y si no se desarrollan esfuerzos institucionales importantes para su esclarecimiento, lo que en otros contextos se calificaría como uso excesivo e ilegal de la fuerza letal puede pasar como un uso legítimo. En una realidad donde la información sobre enfrentamientos es escasa o de baja calidad, el problema de la responsabilidad por el uso de la fuerza se ve seriamente afectado.

Siguiendo al investigador brasileño Ignacio Cano (2003) afirmamos la importancia y necesidad de construir variables e indicadores que permitan registrar el comportamiento de las fuerzas federales y el uso que hacen de la fuerza. Para ello, vemos como posibles fuentes para la construcción de indicadores: a) el número de denuncias o quejas por uso excesivo de la fuerza, incluyendo el uso de la fuerza letal, ante órganos especializados -en México son las Comisiones de Derechos Humanos- que señalan como responsables a policías o militares; b) el número de recomendaciones emitidas por los órganos especializados - Comisiones de Derechos Humanos u organismos internacionales- que versan sobre un uso más razonable de la fuerza; c) el número de procesos judiciales por homicidios dolosos cuyo

menor número de muertos y el mayor número de heridos. La regla obedece a que uno de los objetivos centrales de la base de datos es el cálculo de la tasa de muertos sobre heridos en enfrentamientos. Como partimos de la hipótesis de tasas elevadas de muertos sobre heridos, al existir discrepancia en la información tomamos aquella que juega en contra de nuestras expectativas. Enfrentamientos que no contaban con información en al menos dos periódicos no fueron incluidos en la base de datos. 


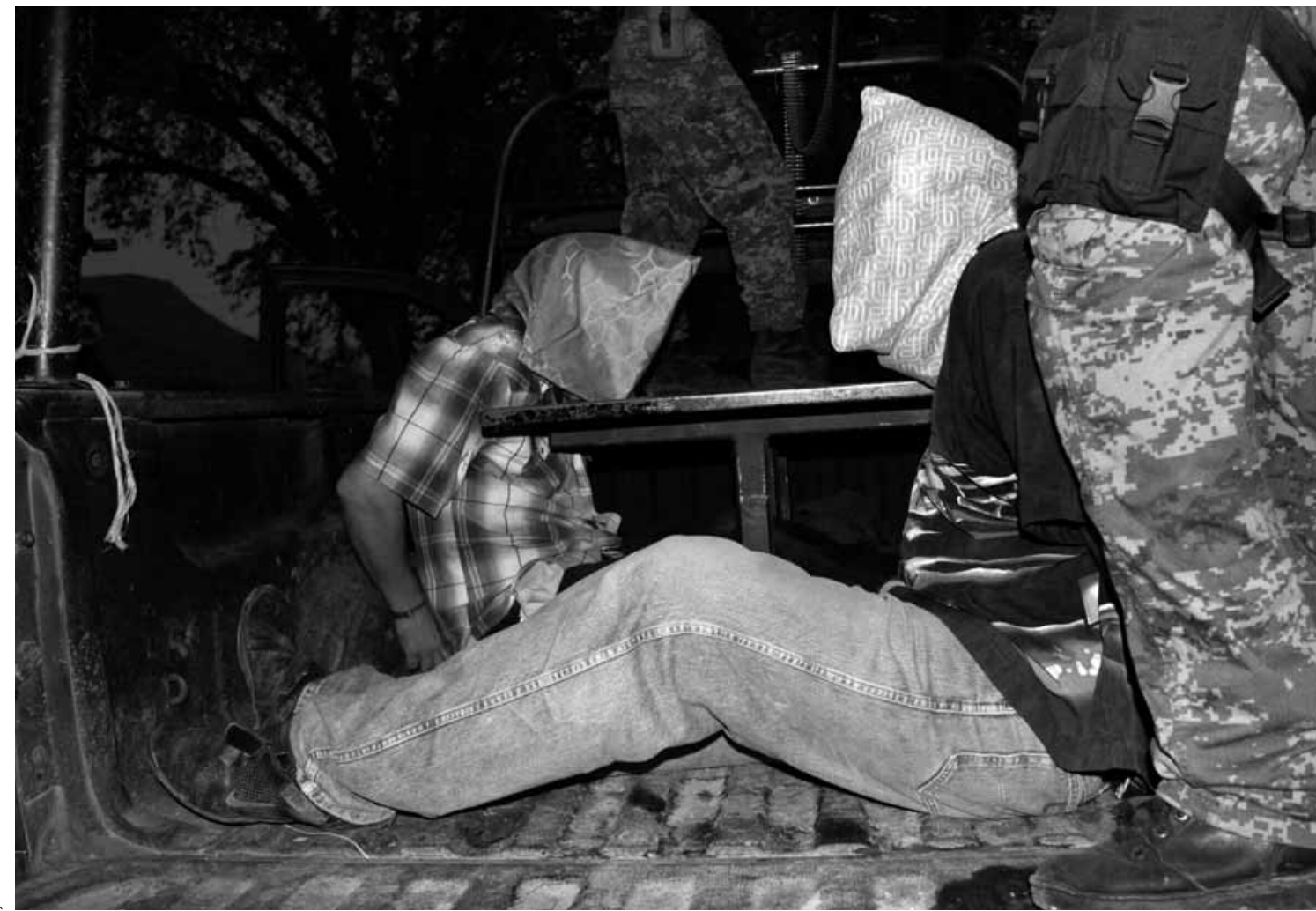

Elementos del Ejército vigilan a dos presuntos gatilleros detenidos después de un enfrentamiento en una casa de seguridad en Guamúchil, Sinaloa, 2011.

presunto responsable es un policía o miembro de otra fuerza de seguridad; $d$ ) indicadores forenses de víctimas de uso letal de la fuerza policial como disparos en la espalda, la cabeza o a quemarropa; e) el número de civiles "opositores"3 muertos por cada "opositor" detenido; f) el número de civiles "opositores" muertos por cada policía u otros miembros de fuerzas de seguridad muertos en enfrentamientos; g) el número de "opositores" muertos por cada "opositor" herido, denominado "índice de letalidad".

Como se muestra en la primera sección de este texto, las quejas ante la CNDH por presuntas violaciones a derechos humanos cometidas por militares, así

\footnotetext{
${ }^{3}$ Se entenderá por "opositores" a los civiles que participaron del enfrentamiento y sobre los que las fuerzas de seguridad dispararon de forma deliberada.
}

como las recomendaciones emitidas por la misma, han aumentado sustantivamente durante el presente sexenio. En lo que resta de este texto, construimos y analizamos los tres últimos indicadores, en particular el llamado "índice de letalidad" en enfrentamientos, a partir de los datos recopilados en nuestra base y de información oficial solicitada a la Sedena o reportada en su Portal de Transparencia y Rendición de Cuentas.

\section{RESULTADOS}

El seguimiento de prensa de enero de 2008 a mayo de 2011 arrojó un saldo general de 224 enfrentamientos entre presuntos miembros de la delincuencia organizada y fuerzas federales. La siguiente 
Tabla 2. Enfrentamientos con presuntos miembros de grupos de delincuencia organizada

\begin{tabular}{|c|c|c|c|c|c|c|c|c|}
\hline Año & $\begin{array}{l}\text { Policía } \\
\text { Federal }\end{array}$ & Ejército & Marina & $\begin{array}{l}\text { Policía } \\
\text { Federal y } \\
\text { Ejército }\end{array}$ & $\begin{array}{c}\text { Policía } \\
\text { Federaly } \\
\text { Marina }\end{array}$ & $\begin{array}{c}\text { Ejército y } \\
\text { Marina }\end{array}$ & $\begin{array}{l}\text { Policía } \\
\text { Federal, } \\
\text { Ejército y } \\
\text { Marina }\end{array}$ & Total \\
\hline 2008 & 13 & 16 & & 10 & & & & 39 \\
\hline 2009 & 13 & 14 & 1 & 9 & & & 2 & 39 \\
\hline 2010 & 10 & 77 & 8 & 6 & 1 & 5 & & 107 \\
\hline \multicolumn{9}{|c|}{ Enero-mayo } \\
\hline Total & 38 & 133 & 14 & 26 & 1 & 9 & 3 & 224 \\
\hline
\end{tabular}

Fuente: Base de datos de enfrentamientos (prensa, enero 2008-mayo 2011).

distribución por año y fuerza de seguridad federal se presenta en la tabla 2. En 2010, los enfrentamientos registrados en la prensa superan la suma de los dos años anteriores. El número de enfrentamientos de los primeros cinco meses de 2011 es igual al registrado durante 2008 y 2009 juntos. Sin embargo, si se mantiene la tendencia para el resto del año, estaría levemente por debajo del de 2010. Destacan los enfrentamientos en los que tiene presencia el Ejército: seis de cada diez enfrentamientos registrados en prensa, considerando aquellos casos en que fueron la única fuerza federal presente, y tres de cada cuatro $-76.3 \%$ - si tomamos en cuenta el total de los enfrentamientos en los cuales participa con otras fuerzas federales.

El total y la distribución de la tabla 2 no representan el universo de enfrentamientos que hubo entre presuntos miembros de la delincuencia organizada y fuerzas federales. La información en prensa refleja sólo una parte de los enfrentamientos - como veremos a partir de la información que ha proporcionado la Sedena- y probablemente existan algunas diferencias sistemáticas entre los enfrentamientos que se registran y los que no se registran en prensa, introduciendo sesgos a la base de datos que deben ser tomados en cuenta. Sin embargo, se trata de casos suficientes para calcular algunos de los indicadores señalados. En la tabla 3 podemos observar el número de fallecidos y de heridos que tuvo como saldo el total de los enfrentamientos registrados. El total de fallecidos de fuerzas de seguridad es casi siete veces menor que el de víctimas civiles. Mientras que en las fuerzas de seguridad el número de heridos es superior al de fallecidos, entre los civiles "opositores" los fallecidos son más de siete veces el número de heridos. Estas relaciones se detallan con mayor precisión en las tablas 4 y 5 .

Para cada fuerza de seguridad federal y para el total se presenta el número de civiles "opositores" fallecidos por cada miembro de la fuerza de seguridad fallecido. ${ }^{4}$ Con base en la información recogida en prensa, en los 38 enfrentamientos en los que participó exclusivamente la Policía Federal fallecieron 1.4 "opositores" por cada policía federal fallecido. Para los 26 enfrentamientos en los que la Policía Federal participó junto al Ejército la tasa es mayor: cuatro civiles "opositores" fallecidos por cada policía federal o soldado fallecido. Si consideramos los

\footnotetext{
${ }^{4} \mathrm{Al}$ tratarse de indicadores para describir el uso de la fuerza letal por parte de las fuerzas de seguridad sólo tomamos a los fallecidos y heridos "opositores" para el cálculo. Podemos considerar que son una consecuencia del uso deliberado de la fuerza de los cuerpos federales de seguridad. En el caso de los civiles "accidentales" no podemos realizar dicha atribución, por lo que no son considerados para el cálculo de las tasas. Se trata de decisiones metodológicas que en ningún caso indican una menor preocupación por las víctimas civiles "accidentales" de los enfrentamientos, que por cierto alcanzan un número importante de fallecidos y heridos, como se aprecia en la tabla 3.
} 
Tabla 3. Saldo del total de enfrentamientos registrados

\begin{tabular}{lcc}
\hline & Fallecidos & Heridos \\
\hline Policías federales & 60 & 66 \\
\hline Soldados & 44 & 110 \\
\hline Marinos & 2 & 18 \\
\hline Policías locales & 10 & 15 \\
\hline Total fuerzas de seguridad & 116 & 209 \\
\hline & & \\
\hline Civiles “opositores” & 756 & 103 \\
\hline Civiles “accidentales” & 44 & 92 \\
\hline Total & 800 & 195 \\
\hline
\end{tabular}

Fuente: Base de datos de enfrentamientos (prensa, enero 2008-mayo 2011).

enfrentamientos en los que participó solamente el Ejército -13.8, sobre 133 enfrentamientos- o la Marina -34.5, aunque sólo contamos con 14 enfrentamientos registrados-, la misma tasa se eleva claramente. No es sencillo establecer un límite definido y único que permita dividir el indicador en valores en

los que sería más probable un uso legítimo de la fuerza y otros en los que la sospecha de casos de uso ilegítimo y excesivo de la fuerza se acrecienta — factores que tienen que ver con las características y el desarrollo de los enfrentamientos pueden hacer variar este umbral-. Sin embargo, los altos valores que adquiere el indicador para el Ejército y la Marina parecen caer en una esfera de preocupación por el posible uso excesivo de la fuerza. Al respecto, Paul Chevigny (1991) sostiene que la muerte de diez o 15 veces más civiles que policías en un periodo dado se considera un indicador que sugiere que la fuerza letal de la policía podría ser usada para propósitos diferentes a la protección de la vida en circunstancias extremas. En la tabla 5 se presenta el índice de letalidad de civiles "opositores" fallecidos sobre civiles "opositores" heridos. ${ }^{5}$

\footnotetext{
${ }^{5}$ Este indicador sólo incorpora en su denominador a los "opositores" heridos y no a los detenidos ilesos. El número de "opositores" fallecidos sobre "opositores" detenidos es un indicador que analizaremos más adelante a partir de datos proporcionados por la Sedena. No incluir a los detenidos ilesos
}

Tabla 4. Presuntos delincuentes fallecidos/policías, soldados o marinos fallecidos

\begin{tabular}{lc}
\hline Policía Federal & 1.4 \\
\hline Ejército & 13.8 \\
\hline Marina & 34.5 \\
\hline Policía Federal y Ejército & 4.0 \\
\hline Fuerzas de seguridad & 6.5 \\
\hline Fuente: Base de datos de enfrentamientos (prensa, enero 2008-mayo 2011).
\end{tabular}

Idealmente, debería esperarse que el número de muertos no sobrepasara por mucho al de heridos y que el valor del índice no fuera superior a uno. Se presentan variaciones importantes en el valor del índice de letalidad según la fuerza federal que consideremos. En los enfrentamientos en los que participó la Policía Federal fallecieron 2.6 civiles "opositores” por cada uno que resultó herido. Los muertos por cada herido se elevan a nueve y a 17 para el Ejército y la Marina, respectivamente. El valor que adquiere el índice de letalidad en otros contextos puede servir de referencia. Con datos oficiales de la Secretaría de Seguridad Pública de São Paulo, disponibles en su página web, es posible calcular el índice de letalidad de la policía militar paulista en intervenciones en las que ha usado armas de fuego (véase tabla 6). El valor más alto corresponde a 2006, con dos civiles fallecidos por cada uno herido, valor más bajo que el $2.6 \mathrm{de}$ la Policía Federal en México, según los registros de prensa. Luego de 2006, el índice de letalidad de la policía militar en São Paulo desciende año con año.

Una investigación sobre el sesgo racial del uso de la fuerza letal por parte de la Policía Militar de Río

en el cálculo no es una "omisión" o un sesgo deliberado. La preocupación detrás del índice de letalidad es que cuando se recurre al empleo de la fuerza letal se espera un saldo de muertos y de heridos. Es decir, al intentar detener la acción de un "opositor" lo suficientemente grave como para que se use fuerza letal en su contra - fuerza que debe cesar al mismo tiempo que la acción o amenaza-, el resultado no siempre debería ser su fallecimiento. La preocupación acerca de la existencia de casos de uso excesivo de la fuerza letal cuenta con mayor sustento si el número de muertos es más alto que el de heridos. 
Tabla 5. Índice de letalidad de presuntos delincuentes fallecidos sobre presuntos delincuentes heridos

\begin{tabular}{lc}
\hline Policía Federal & 2.6 \\
\hline Ejército & 9.1 \\
\hline Marina & 17.3 \\
\hline Policía Federal y Ejército & 4.8 \\
\hline Fuerzas de seguridad & 7.3 \\
\hline Fuente: Base de datos de enfrentamientos (prensa, enero 2008-mayo 2011).
\end{tabular}

de Janeiro (Cano, 2010) arroja valores más altos y preocupantes del índice de letalidad, en especial al tomar en cuenta características raciales de los "opositores", así como los contextos espaciales de ocurrencia de los enfrentamientos. Con datos de reportes oficiales de la policía sobre el uso de la fuerza, durante la década de los noventa, un periodo de alta preocupación por abusos en el uso de la fuerza cometidos por miembros de la Policía Militar de Río de Janeiro, Ignacio Cano calcula el valor de índices de letalidad (véase tabla 7 ).

En Río de Janeiro el índice de letalidad adquiere los valores más altos en el caso de "opositores" cuya raza es distinta a la "blanca" y cuando los enfrentamientos tienen como escenario las favelas - los barrios más populares y carenciados de la ciudad-. Bajo dichos condicionantes el índice alcanza valores de ocho y nueve civiles "opositores" muertos por cada herido, un resultado similar al que presenta el Ejército en México según la tabla 5. Estos resultados y comparaciones refuerzan la hipótesis acerca del uso excesivo de la fuerza letal por parte del Ejército y de la Marina en México. Sin embargo, hay que tomar precauciones con referencia a la cobertura y posible sesgo de los datos a partir de la fuente utilizada, así como la existencia de hipótesis alternativas que puedan dar seguimiento a los niveles y variaciones en los resultados presentados. Es importante contrastar la información de la base de prensa con la de otras fuentes para saber si los valores y las diferencias observadas son similares. Con esa finalidad se
Tabla 6. Índice de letalidad de la Policía de São Paulo

\begin{tabular}{ll}
\hline$A \tilde{n} o$ & \\
\hline 2006 & 2.06 \\
\hline 2007 & 1.07 \\
\hline 2008 & 0.85 \\
\hline 2009 & 0.61 \\
\hline 2010 & 0.55 \\
\hline
\end{tabular}

Fuente: Cálculo con base en información disponible en página electrónica <http://www.ssp.sp.gov.br/estatistica/trimestrais.aspx\#>

analizó información que reporta la Sedena en su Portal de Transparencia, recalculando el índice de letalidad, pero en esta ocasión comparando su evolución de 2008 a 2011.

Con un total de 3181 civiles fallecidos y 540 civiles heridos, el índice de letalidad construido con los datos aportados por la Sedena es de 5.9 para el periodo de 2008 a 2011.6 Si consideramos la información de esta dependencia hasta mayo de 2011, al igual que la base de datos de prensa, el índice de letalidad es de 6.3. En ambos casos se trata de valores inferiores a los ocho civiles fallecidos por cada civil herido que da como resultado la base de datos de prensa si se toman en cuenta todos los enfrentamientos en los que participó el Ejército. ${ }^{7}$ La diferencia podría deberse a que en la prensa nacional suelen registrarse

${ }^{6} \mathrm{Si}$ aceptamos los datos de la Sedena como un registro idóneo de los muertos y heridos de los enfrentamientos en los que participó el Ejército, la base de datos de seguimiento de prensa sólo nos ha permitido captar $40 \%$ de estos casos, considerando los datos del Ejército solamente hasta mayo del 2011. Es posible que los enfrentamientos con saldos de pocos o ningún fallecido no hayan sido publicados en la prensa nacional por su menor impacto mediático. De esta forma, la base de datos presentaría un sesgo a la alza en el cálculo del índice de letalidad.

${ }^{7}$ En la tabla 5 el valor del índice de letalidad para el Ejército según reportes de prensa fue de 9.1. Se consideraron los enfrentamientos donde se reportó presencia exclusivamente del Ejército. Si se toman en cuenta todos los enfrentamientos en los que el Ejército participó el valor es de 8.1. Como la Sedena reporta información sobre todos los enfrentamientos en que el Ejército tiene parte, comparamos el índice de letalidad resultante de su información con este último valor. 
Tabla 7. Índice de letalidad de “opositores” en intervenciones policiales. Policía Militar de Río de Janeiro, 1996-1999

\begin{tabular}{lcccc} 
& Área & Blancos & Mulatos & Negros \\
\hline Fuera de favela & 1.9 & 3.2 & 2.6 \\
\hline Dentro de favela & 4.6 & 9 & 8.2 \\
\hline
\end{tabular}

Fuente: Ignacio Cano, 2010, “Racial Bias in Police Use of Lethal Force in Brazil”, en Police and Practice Research, vol. 11, núm. 1, pp. $31-43$.

enfrentamientos donde el número de fallecidos es elevado. Los datos de la Sedena nos muestran que el índice de letalidad ha crecido significativamente a partir de 2010. A partir de ese año aumentaron los enfrentamientos en los que participó el Ejército y con ellos el saldo total de heridos y muertos, estos últimos en particular. Los valores del índice de letalidad de 2010 y 2011 se sitúan por debajo de los valores más altos que se reportan para la Policía Militar de Río de Janeiro. Sin embargo, tal como lo constata el estudio brasileño, el uso de la fuerza letal aumenta bajo distintas condiciones, muchas de ellas ilegítimas, como las características raciales o sociales de los

“opositores". Para el caso del Ejército en México queremos subrayar dos variaciones en el índice de letalidad: el ya mencionado aumento del índice desde 2010 y los valores que alcanza en 2010 y 2011 en estados del país donde ha sido mayor la presencia y el número de enfrentamientos del Ejército con grupos de delincuencia organizada.

En 2010 y 2011 las dos terceras partes de los civiles fallecidos en enfrentamientos se concentraron en tres estados: Tamaulipas, Nuevo León y Guerrero (véase tabla 9). El índice de letalidad en Tamaulipas adquiere los valores más elevados del país — también por encima de los presentados para la Policía Militar de Río de Janeiro en los años noventa y en sus escenarios más problemáticos-. En Nuevo León en ambos años el saldo de los enfrentamientos fue de alrededor de siete civiles fallecidos por cada herido, mientras que en Guerrero aumenta más de $50 \%$ en un año llegando a más de nueve fallecidos por cada herido en 2011. ¿Por qué en los enfrentamientos de los dos últimos años, mayores en número que los de años anteriores, se eleva de manera tan significativa el saldo de muertos sobre el de heridos? ¿Qué caracteriza a los enfrentamientos de los estados donde el índice de letalidad es claramente mayor y alcanza valores tan elevados? Las preguntas traen consigo la necesidad de mejores descripciones, indicadores y controles acerca del uso de la fuerza por parte del Estado. Las respuestas válidas no serán únicas y habrá más de un factor explicativo, pero las posibilidades de un uso sistemático y excesivo de la fuerza no pueden dejar de considerarse en toda su profundidad y consecuencias.

\section{Relación fallecidos/detenidos en enfrentamientos}

Los datos aportados por la Sedena nos permiten analizar otro indicador en relación con las prácticas de uso de la fuerza por parte del Ejército de 2008 a 2011: la tasa de civiles fallecidos sobre civiles detenidos - ya sean heridos o ilesos - en enfrentamientos con presuntos miembros de grupos de delincuencia organizada. El resultado global de los datos de la Sedena para ese periodo es de 3181 civiles fallecidos y 2556 detenidos en enfrentamientos. Es decir, una tasa global de 1.24 civiles fallecidos por cada civil detenido. Sin embargo, más interesante que el resultado global es la variación por año en diferentes estados del país.

La tabla 10 nos permite apreciar dos aspectos: por un lado, tanto el número de fallecidos como de detenidos creció año con año; por el otro, en los últimos dos años hubo cada vez más muertos en enfrentamientos en relación con los detenidos. Esta última variación se refleja con claridad en el aumento de la tasa de muertos sobre detenidos. Si tomamos los 
Tabla 8. Civiles muertos y heridos en enfrentamientos con el Ejército, 2008-2011

\begin{tabular}{lccccc}
\hline \multicolumn{1}{c}{ Datos Sedena } & 2008 & 2009 & 2010 & 2011 & Total \\
\hline Civiles muertos & 71 & 211 & 734 & 2165 & 3181 \\
\hline Civiles heridos & 26 & 71 & 108 & 335 & 540 \\
\hline Índice de letalidad & 2.73 & 2.97 & 6.80 & 6.46 & 5.89 \\
\hline
\end{tabular}

Fuente: Elaborado con información proporcionada por la Sedena.

valores extremos del periodo, apreciamos que mientras en 2009 hubo más de dos detenidos por cada fallecido en enfrentamientos - 0.42-, en 2011 la relación se invierte con 1.99 , casi dos fallecidos, por cada detenido. Igual que en el caso del índice de letalidad, presentamos las variaciones de la tasa de fallecidos sobre detenidos civiles para los estados del país donde el nivel de enfrentamiento del Ejército con grupos de delincuencia organizada ha sido más intenso en los últimos años. En Tamaulipas, Nuevo León y Guerrero se observa la misma tendencia al incremento de la tasa de fallecidos sobre detenidos de 2009 a 2011 que veíamos en la tabla anterior. Es decir, la tendencia nacional obedece en buena medida al resultado de los enfrentamientos en dichas entidades federativas. Entre los valores más elevados de la tasa destacan los de 2011, en particular en Tamaulipas y Guerrero, con casi tres fallecidos por cada detenido -2.82- y más de tres muertos por cada detenido - 3.24-, respectivamente.

\section{EJECUCIONES EXTRAJUDICIALES, SUMARIAS O ARBITRARIAS EN EL DERECHO INTERNACIONAL DE LOS DERECHOS HUMANOS}

Desde el paradigma de los derechos humanos, el uso de la fuerza letal debe ser una excepción y aquellas muertes que se produzcan al poner en práctica acciones que no atiendan en su ejecución a los principios y estándares del derecho internacional pueden ser consideradas ejecuciones extrajudiciales, sumarias o arbitrarias, de las que se puede desprender una responsabilidad directa hacia el Estado. Estas situaciones aumentan su probabilidad de ocurrencia bajo políticas de seguridad que privilegian la utilización de fuerzas de seguridad, como el Ejército o la Marina, en funciones cuya naturaleza es totalmente diferente, como las que ha emprendido el Gobierno de la República desde hace cinco años.

Para poder determinar cuándo el uso de la fuerza es excesivo y viola el derecho internacional se han desarrollado normas y principios de la mayor relevancia. Los dos documentos clave son el Código de conducta para funcionarios encargados de hacer cumplir la ley (OACNUdH, 1979) y los Principios básicos sobre el empleo de la fuerza y de armas de fuego por los funcionarios encargados de hacer cumplir la ley (OACNUDH, 1990). Ambos documentos son fundamentales para definir los límites que el ámbito de los derechos humanos impone a los funcionarios del Estado -incluidos policías y soldados- en su lucha por hacer cumplir la ley. La importancia y legitimidad de los mismos deriva de la amplia discusión y consenso de la que son resultado, ya que su creación y aprobación son producto de la participación de múltiples Estados y su contenido cuenta con un consenso cuasi universal, que además se ha nutrido de la jurisprudencia internacional.

No debe perderse de vista que estas normas surgen de la obligación que tienen todos los Estados de proteger el derecho a la vida como un derecho fundamental y que por ello ha sido establecido en múltiples Convenios y Pactos Internacionales, comenzando por el artículo $6^{\circ}$ del Pacto Internacional de Derechos Civiles y Políticos. Sobre este derecho, el Comité de Derechos Humanos, en su Observación General núm. 6, ha determinado que se trata de "el derecho supremo respecto del cual no se autoriza 
Tabla 9. Civiles fallecidos en enfrentamientos, 2010-2011

\begin{tabular}{lccccccccc}
\hline & \multicolumn{2}{c}{ Tamaulipas } & \multicolumn{2}{c}{ Nuevo León } & \multicolumn{2}{c}{ Guerrero } & \multicolumn{3}{c}{ Resto del país } \\
& 2010 & 2011 & 2010 & 2011 & 2010 & 2011 & 2010 & 2011 \\
\hline Civiles muertos & 353 & 802 & 133 & 426 & 49 & 188 & 199 & 749 \\
\hline Civiles heridos & 28 & 79 & 18 & 61 & 8 & 20 & 54 & 175 \\
\hline Índice de letalidad & 12.61 & 10.15 & 7.39 & 6.98 & 6.13 & 9.40 & 3.69 & 4.28 \\
\hline
\end{tabular}

Fuente: Elaborado con información proporcionada por la Sedena.

suspensión alguna, ni siquiera en situaciones que pongan en peligro la vida de la nación”. Asimismo, la Corte Interamericana de Derechos Humanos ha establecido que:

El derecho a la vida es un derecho humano fundamental, cuyo goce pleno es un prerrequisito para el disfrute de todos los demás derechos humanos. De no ser respetado, todos los derechos carecen de sentido. En razón de dicho carácter, no son admisibles enfoques restrictivos del mismo (Corte Interamericana de Derechos Humanos).

La condición de irreversibilidad de la muerte es una de las razones por las que el derecho internacional establece rigurosas salvaguardias de este derecho y por ello, como lo ha determinado el relator especial de la Organización de las Naciones Unidas (ONU) sobre ejecuciones extrajudiciales:

un procedimiento jurídico que respete las garantías procesales debidas y llegue a una sentencia definitiva es un requisito esencial sin el cual la decisión de un Estado y de sus agentes de dar muerte a alguien viola el principio de "nadie podrá ser privado de la vida arbitrariamente" y por lo tanto violaría el derecho a la vida (caso de la masacre de Pueblo Bello contra Colombia, sentencia del 31 de enero de 2006, serie C, núm. 140).

Tanto en el Código de conducta para funcionarios - artículo $3^{\circ}$ - y en los Principios básicos sobre el empleo de la fuerza - art. $9^{\circ}$ - se estipulan los principales criterios para el uso de la fuerza del Estado. Nos referimos a los principios de proporcionalidad y necesidad que son la clave de bóveda para la discusión en la materia. Por lo que tiene que ver con el principio de proporcionalidad, en el párrafo $b$ del comentario que se agrega para precisar el artículo $3^{\circ}$ del Código de conducta se establece: "En ningún caso debe interpretarse que esta disposición autoriza el uso de un grado de fuerza desproporcionado al objeto legítimo que se ha de lograr". Como lo ha señalado Alston, este requisito de proporcionalidad:

impone un límite absoluto al nivel tolerable de fuerza sobre la base de la amenaza a otras personas planteada por el sospechoso. [...] Podría afirmarse que la proporcionalidad define el punto en que las vidas y el bienestar de otras personas justifican el uso de la

Tabla 10. Civiles muertos y detenidos en enfrentamientos y tasa de muertos sobre detenidos en enfrentamientos del Ejército y presuntos miembros de la delincuencia organizada, 2008-2011

\begin{tabular}{lcccc}
\hline & 2008 & 2009 & 2010 & 2011 \\
\hline Civiles muertos & 71 & 211 & 734 & 2165 \\
\hline Civiles detenidos & 117 & 506 & 847 & 1086 \\
\hline Civiles muertos/civiles detenidos & 0.61 & 0.42 & 0.87 & 1.99 \\
\hline
\end{tabular}

Fuente: Elaborado con información proporcionada por la Sedena. Solicitud de acceso a la información, folio núm. 0000700194411. 
Tabla 11. Civiles muertos y detenidos y tasa de muertos sobre detenidos en enfrentamientos del Ejército con presuntos miembros de la delincuencia organizada:

Tamaulipas, Nuevo León, Guerrero y resto del país, 2008-2011

\begin{tabular}{|c|c|c|c|c|c|c|c|c|c|c|c|c|c|c|c|c|}
\hline & \multicolumn{4}{|c|}{ Tamaulipas } & \multicolumn{4}{|c|}{ Nuevo León } & \multicolumn{4}{|c|}{ Guerrero } & \multicolumn{4}{|c|}{ Resto del país } \\
\hline & 2008 & 2009 & 2010 & 2011 & 2008 & 2009 & 2010 & 2011 & 2008 & 2009 & 2010 & 2011 & 2008 & 2009 & 2010 & 2011 \\
\hline $\begin{array}{l}\text { Civiles } \\
\text { muertos }\end{array}$ & 5 & 28 & 353 & 802 & 0 & 24 & 133 & 426 & 14 & 49 & 49 & 188 & 52 & 110 & 199 & 749 \\
\hline $\begin{array}{l}\text { Civiles } \\
\text { detenidos }\end{array}$ & 35 & 100 & 187 & 284 & 5 & 63 & 145 & 216 & 6 & 28 & 51 & 58 & 71 & 315 & 464 & 528 \\
\hline $\begin{array}{l}\text { Civiles } \\
\text { muertos/ } \\
\text { civiles } \\
\text { detenidos }\end{array}$ & 0.14 & 0.28 & 1.89 & 2.82 & $(-)$ & 0.38 & 0.92 & 1.97 & 2.33 & 1.75 & 0.96 & 3.24 & 0.73 & 0.35 & 0.43 & 1.42 \\
\hline
\end{tabular}

Fuente: Elaborado con información proporcionada por la Sedena. Solicitud de acceso a la información, folio núm. 0000700194411.

fuerza contra el sospechoso y que, si se supera ese punto, el uso de la fuerza no estaría justificado y, de causar la muerte, sería una violación del derecho a la vida. La norma general de proporcionalidad es que el uso de la fuerza debe estar en proporción a la gravedad del delito y al objetivo legítimo que se persiga (Alston, 2006).

Por su parte, los Principios básicos establecen en relación con el principio de proporcionalidad:

Los funcionarios encargados de hacer cumplir la ley no emplearán armas de fuego contra las personas salvo en defensa propia o de otras personas, en caso de peligro inminente de muerte o lesiones graves, o con el propósito de evitar la comisión de un delito particularmente grave que entrañe una seria amenaza para la vida, o con el objeto de detener a una persona que represente ese peligro y oponga resistencia a su autoridad, o para impedir su fuga (OACNUDH, 1990).

De acuerdo con el relator especial, en este caso el concepto de proporcionalidad es claro y supone que a un funcionario se le permite matar excepcionalmente sólo para proteger la vida de otras personas. Como él mismo advierte: "La cuestión fundamental es la proporcionalidad entre la probabilidad objetiva previsible de que el uso de la fuerza cause la muerte y la probabilidad previsible comparable de que no reducir a la persona cause la muerte de otras personas".

Por lo que tiene que ver con el principio de necesidad es importante citar el artículo $3^{\circ}$ del Código de conducta, donde se estipula: "Los funcionarios encargados de hacer cumplir la ley podrán usar la fuerza sólo cuando sea estrictamente necesario y en la medida que lo requiera el desempeño de sus tareas". Este requisito de necesidad implica que los policías o soldados tienen la obligación de reducir al mínimo el nivel de fuerza en sus intervenciones, independientemente del nivel de fuerza que sería proporcional. En relación con las armas de fuego, este principio exige que sólo se acuda a ellas en el caso de que resulten insuficientes medidas menos extremas para lograr los objetivos planteados. Como se indica en los Principios básicos: "Podrán utilizar la fuerza y armas de fuego solamente cuando otros medios resulten ineficaces o no garanticen de ninguna manera el logro del resultado previsto" (Principio 4). Lo anterior es reforzado por el comentario al artículo $3^{\circ}$ del Código de conducta:

El uso de armas de fuego se considera una medida extrema. [...] En general, no deberán emplearse armas de fuego excepto cuando un presunto delincuente ofrezca resistencia armada o ponga en 
peligro, de algún otro modo, la vida de otras personas y no pueda reducirse o detenerse al presunto delincuente aplicando medidas menos extremas (párrafo $c$ del comentario al artículo $3^{\circ}$ del Código de conducta).

Todo lo anterior refuerza los Principios relativos a una eficaz prevención e investigación de las ejecuciones extralegales, arbitrarias o sumarias recomendados por el Consejo Económico y Social en su resolución 1985/65 de 24 de mayo de 1989, de los cuales cito los tres primeros párrafos:

1. Los gobiernos prohibirán por ley todas las ejecuciones extralegales, arbitrarias o sumarias y velarán por que todas esas ejecuciones se tipifiquen como delitos en su derecho penal y sean sancionables con penas adecuadas que tengan en cuenta la gravedad de tales delitos. No podrán invocarse para justificar esas ejecuciones circunstancias excepcionales, como por ejemplo el estado de guerra o de riesgo de guerra, la inestabilidad política interna ni ninguna otra emergencia pública. Esas ejecuciones no se llevarán a cabo en ninguna circunstancia ni siquiera en situaciones de conflicto armado interno, abuso o uso ilegal de la fuerza por parte de un funcionario o de otra persona que actúe con carácter oficial o de una persona que obre a instigación, o con el consentimiento o la aquiescencia de aquélla, ni tampoco en situaciones en las que la muerte se produzca en prisión.

2. Con el fin de evitar las ejecuciones extralegales, arbitrarias o sumarias, los gobiernos garantizarán un control estricto, con una jerarquía de mando claramente determinada, de todos los funcionarios responsables de la captura, detención, arresto, custodia y encarcelamiento, así como de todos los funcionarios autorizados por la ley para usar la fuerza y las armas de fuego.

3. Los gobiernos prohibirán a los funcionarios superiores o autoridades públicas que den órdenes en que autoricen o inciten a otras personas a llevar a cabo cualquier ejecución extralegal, arbitraria o sumaria. Toda persona tendrá el derecho y el deber de negarse a cumplir esas órdenes. En la formación de esos funcionarios encargados de hacer cumplir la ley deberá hacerse hincapié en las disposiciones expuestas (Prin- cipios relativos a una eficaz prevención e investigación de las ejecuciones extralegales, arbitrarias o sumarias).

Estos planteamientos son fundamentales para poder determinar en qué circunstancias se está frente a un uso legítimo de la fuerza y en cuáles se están violando las normas y los principios establecidos en el orden internacional y, por tanto, incurriendo en responsabilidad directa. La ejecución de sospechosos no sólo es contraria al derecho internacional, sino que además la historia en nuestro Continente ha mostrado en múltiples ocasiones los riesgos a mediano plazo que dichas acciones de lucha contra la delincuencia suponen para la sociedad. Como señala el relator especial de la onu para las ejecuciones extrajudiciales:

vista desde fuera, la retórica de la mano dura se parece sorprendentemente a la de la doctrina de "seguridad nacional" que muchos Estados de América Latina practicaron durante los años setenta y primeros ochenta, y que tuvo resultados absolutamente desastrosos (Alston, 2007: 22).

Por ello es importante recordar que, precisamente, una de las recomendaciones emitidas al gobierno mexicano en 1999, en el Informe E/CN.4/2000/3/ Add. 3 de la relatora especial, Asma Jahangir, relativo a las ejecuciones extrajudiciales, sumarias o arbitrarias fue la de que se cumpla "la desmilitarización de la sociedad y evite delegar en las fuerzas armadas el mantenimiento del orden público o la lucha contra el delito". Sin embargo, como se ha hecho notar en este documento, el gobierno federal mexicano ha desatendido dicha recomendación impulsando, cada vez más, el uso de las fuerzas armadas para las funciones de seguridad pública. La pregunta sobre si la situación de México cae dentro de los supuestos del derecho internacional sobre ejecuciones extrajudiciales está abierta, pero es ineludible. En todo caso, México ha postergado la visita que solicitó el nuevo relator especial sobre ejecuciones extrajudiciales, Philip Alston. 


\section{CONCLUSIONES}

Resulta indispensable llevar registro de y hacer públicas las muertes que tienen como responsables a un servidor público, especialmente cuando es miembro de las fuerzas armadas o de seguridad pública. Como mencionamos en la introducción de este texto, si el uso de la fuerza se desarrolla en condiciones de información insuficiente sobre su ejercicio y con base en procedimientos inadecuados de control y eventual determinación de responsabilidades, aumenta la posibilidad de su abuso. Además, es conveniente explorar otras variables vinculadas a los enfrentamientos - por ejemplo, el tipo de armamento de los "opositores" según los grupos criminales y espacios privilegiados donde se desarrollaron año con año- que pudieran explicar, desde otras variables, una parte del aumento en el uso de la fuerza. También es necesario triangular la información de los enfrentamientos con otros posibles indicadores e investigaciones, cuantitativas y cualitativas -algunos de esos posibles indicadores ya han sido mencionados, por ejemplo, a partir de estadísticas periciales para fallecidos en enfrentamientos-.

El impacto negativo que la "guerra contra las drogas" ha tenido en el Ejército tampoco puede ser dejado a un lado. Las encuestas de Latinbarómetro ${ }^{8}$ revelan que de 2006 a 2009 ha disminuido el porcentaje de ciudadanos que muestran confianza hacia las fuerzas armadas. Estos datos exponen que en 2009 aumentó el porcentaje de ciudadanos que externaron poca confianza hacia las fuerzas armadas, poniéndose por encima de aquellos que refirieron tener mucha confianza. Esta pérdida de confianza no puede ser entendida fuera del contexto actual en el que la participación de las fuerzas armadas es una parte central de la estrategia del gobierno federal en el combate al narcotráfico. La inclusión del Ejército en tareas de seguridad, en entornos violentos, parece traer consigo un inevitable uso de la fuerza bajo

\footnotetext{
${ }^{8}$ Disponibles en la página electrónica: <http://www.latinobarometro.org>.
}

una lógica de guerra, y posiblemente sea difícil otro resultado a partir de las características de la formación militar. Los datos aquí presentados deben tomarse en cuenta al reflexionar sobre la autorización, los límites y las posibilidades de involucramiento del Ejército y la Marina en labores de seguridad pública. Tampoco pueden dejar de considerarse las exigencias que plantean en materia de información, construcción de indicadores y controles - legales, institucionales y sociales- sobre los abusos en el uso de la fuerza, en particular de la fuerza letal. Las decisiones que se tomen condicionarán el tipo de Estado en el que viviremos y las relaciones que como sociedad podamos tener con la autoridad.

\section{Bibliografía}

Alston, Philip, 2006, "Informe provisional sobre la situación mundial con respecto a las ejecuciones extrajudiciales, sumarias o arbitrarias", A/61/311, 5 de septiembre, Organización de las Naciones Unidas, Nueva York.

_ 2007, "Informe del relator especial con respecto a ejecuciones extrajudiciales, sumarias o arbitrarias", A/HRC/4/20/Add.2, 19 de febrero, Organización de las Naciones Unidas, Nueva York.

Amnistía Internacional (AI), 2009, "México: nuevos informes de violaciones de derechos humanos a manos del Ejército, 2009", en línea: <http://amnistia.org.mx/ abusosmilitares/informe.pdf $>$.

Birkbeck, Chistopher y Luis G. Gabaldón, 2002, "Estableciendo la verdad sobre el uso de la fuerza en la policía venezolana”, en Revista Nueva Sociedad, núm. 182, Caracas, pp. 47-58.

Cano, Ignacio, 2003, La policía y su evaluación. Propuestas para la construcción de indicadores de evaluación en el trabajo policial, Centro de Estudios para el Desarrollo, Área Seguridad Ciudadana, Santiago de Chile, en línea: $<w w w . p o l i c i a y s o c i e d a d . o r g>$.

_ 2010, "Racial Bias in Police Use of Lethal Force in Brazil", en Police and Practice Research, vol. 11, núm. 1, pp. 31-43.

Centro de Estudios Legales y Sociales (CELs), 2002, Violencia y enfrentamientos policiales, Centro de Estudios Legales y Sociales, Buenos Aires.

Cervantes, Arturo, 2011, "Epidemiology of Homicide and Costs of Violence in México", ponencia, en Forum on 
Global Violence Prevention, Institute of Medicine Washington D. C., Institute of Medicine of the National Academies, Secretaría de Salud, 28-29 de abril, México. Chevigny, Paul, 1991, "Police Deadly Force as Social Control: Jamaica, Brazil and Argentina”, en Série Dossie Núcleo de Estudos da Violencia, Universidad de São Paulo, núm. 2, p. 10.

Comisión Nacional de Derechos Humanos (CNDH), 2006, Informes de actividades, Comisión Nacional de Derechos Humanos, México, en línea: <http://www.cndh.org.mx>.

— 2007, Informes de actividades, Comisión Nacional de Derechos Humanos, México, en línea: <http:// www.cndh.org.mx/node/120>.

— 2008 , Informes de actividades, Comisión Nacional de Derechos Humanos, México, en línea: <http:// www.cndh.org.mx/node/120>.

- 2009, Informes de actividades, Comisión Nacional de Derechos Humanos, México, en línea: <http:// www.cndh.org.mx/node/120>.

- 2010, Informes de actividades, Comisión Nacional de Derechos Humanos, México, en línea: <http:// www.cndh.org.mx/node/120>.

Escalante Gonzalbo, Fernando, 2011, "Homicidios 20082009. La muerte tiene permiso”, en Nexos, núm. 397, en línea: <http://www.nexos.com.mx/?P=leerarticulo \&Article $=1943189>$.

Guerrero Gutiérrez, Eduardo, 2011, "La raíz de la violencia”, en Nexos, núm. 402, en línea: <http://www.nexos. com.mx/?P=leerarticulo\&Article $=2099328>$.

Human Rights Watch (HRW), 2011, "Ni seguridad, ni derechos: ejecuciones, desapariciones y tortura en la 'guerra contra el narcotráfico", en línea: <http://www.hrw.org/ es/reports/2011/11/09/ni-seguridad-ni-derechos $>$.

- 2012, Informe mundial 2012, en línea: <http:// www.hrw.org/sites/default/files/related_material/ wr2012spwebwcover-1.pdf $>$.

Jahangir, Asma, 1999, "Informe de la relatora especial relativo a las ejecuciones extrajudiciales sumarias o arbitrarias", Comisión de Derechos Humanos, Organización de Naciones Unidas, en línea: <http://daccess-dds-ny.un. org/doc/UNDOC/GEN/G99/100/22/PDF/G9910022. pdf?OpenElement $>$.
Latinobarómetro, Opinión Pública Latinoamericana, en línea: <http://www.latinobarometro.org >, consultado el 27 de marzo de 2011.

Merino, José, 2011, "Los operativos conjuntos y la tasa de homicidios: una medición”, en Nexos, núm. 402, en línea: <http://www.nexos.com.mx/?P=leerarticulo\&Art icle $=2099329>$.

Meyer, Maureen, Stephanie Brewer y Carlos Cepeda, 2010, Abuso y miedo en Ciudad Juárez, un análisis de violaciones a los derechos humanos cometidas por militares en México, Washington Office in Latin America, Centro de Derechos Humanos Miguel Agustín Pro Juárez, Washington.

Oficina del Alto Comisionado de las Naciones Unidas para los Derechos Humanos (OACNUDH), 1979, Código de conducta para funcionarios encargados de hacer cumplir la ley, Resolución 34/169 de la Asamblea General, 17 de diciembre, México, en línea: $<$ http://www. ordenjuridico.gob.mx/TratInt/Derechos\%20Humanos/OTROS\%2002.pdf>.

, 1990, Principios básicos sobre el empleo de la fuerza y de armas de fuego por los funcionarios encargados de hacer cumplir la ley, Octavo Congreso de las Naciones Unidas sobre Prevención del Delito y Tratamiento del Delincuente, 27 de agosto-7 de septiembre, La Habana, en línea: <http://www.juridicas.unam.mx/publica/librev/rev/derhum/cont/17/pr/pr11.pdf $>$.

Secretariado Ejecutivo, Sistema Nacional de Seguridad Pública, 2010, Presentación de Incidencia Delictiva, Delitos del Fuero Común de mayor impacto, XXX Consejo Nacional de Seguridad Pública, México, en línea: $<$ http://www.secretariadoejecutivo.gob.mx/es/SecretariadoEjecutivo/Delitos_del_Fuero_Comun_de_ Mayor_Impacto_Graficos_Presentados_en_la_XXX_ Sesion_del_CNSP $>$.

Secretaría de la Defensa Nacional (Sedena), 2006-2011, "Informes anuales", en línea: <www.sedena.gob.mx>.

Waly Ndiaye, Bacre, 1994, "Informe del relator especial sobre ejecuciones extrajudiciales, sumarias o arbitrarias", Comisión de Derechos Humanos, Organización de Naciones Unidas, en línea: <http://daccess-ddsny.un.org/ doc/UNDOC/GEN/G93/858/12/PDF/G9385812.pdf? OpenElement>. 